\title{
Characterization of copper manganite oxide-polypyrrole composite electrodes cathodically polarized in acidic medium
}

\author{
J.F. Marco ${ }^{\mathrm{a}, *}$, J.R. Gancedo ${ }^{\mathrm{a}}$, H. Nguyen Cong ${ }^{\mathrm{b}}$, K. El Abbassi ${ }^{\mathrm{b}}$, \\ M. del Canto ${ }^{c}$, E. Ríos ${ }^{c}$, J.L. Gautier ${ }^{\text {c } * *}$ \\ a Instituto de Química-Física "Rocasolano”, CSIC, c/ Serrano 119, 28006 Madrid, Spain \\ ${ }^{\mathrm{b}}$ Laboratoire commun au CNRS et à l'Université Louis Pasteur, LC 3, UMR 7177, 1-4 rue Blaise Pascal, 67000 Strasbourg, France \\ ${ }^{c}$ Departamento de Química de los Materiales, Facultad de Química y Biología, USACH, Avda. Lib. B. O’Higgins 3363, Santiago, Chile \\ Received 6 January 2007; received in revised form 15 June 2007; accepted 23 July 2007 \\ Available online 31 July 2007
}

\begin{abstract}
We have studied the electrochemical behaviour induced by polarization in sandwich-type composite electrodes with the structure GC/PPy/PPy $(\mathrm{Ox}) / \mathrm{PPy}$ where GC stands for glassy carbon, PPy for polypyrrole and $\mathrm{Ox}$ for $\mathrm{Cu}_{1.4} \mathrm{Mn}_{1.6} \mathrm{O}_{4}$ nanoparticles. The electrodes were polarized at $-0.45 \mathrm{~V} / \mathrm{SCE}$ in $0.15 \mathrm{M} \mathrm{KCl}$ aqueous solution at $\mathrm{pH} 2.2$ either saturated in $\mathrm{Ar}$ or $\mathrm{O}_{2}$ at $25^{\circ} \mathrm{C}$. The changes occurring on these electrodes were studied using X-ray photoelectron spectroscopy (XPS) and X-ray absorption spectroscopy (EXAFS and XANES) techniques. In previous work we have shown that when the oxide particles are incorporated into the PPy matrix the $\mathrm{Cu}^{+}$present in the initial oxide suffers dismutation to give $\mathrm{Cu}^{2+}$ and metallic $\mathrm{Cu}$. In this work we show that the polarized electrodes also reveal the presence of metallic $\mathrm{Cu}$ and $\mathrm{Cu}^{2+}$. The data also show that the oxide particles embedded in the polarized electrodes contain $\mathrm{Mn}^{3+}$ and $\mathrm{Mn}^{4+}$, although the $\mathrm{Mn}^{3+} / \mathrm{Mn}^{4+}$ ratio is different from that found in the fresh electrodes. The $\mathrm{Cl} 2 \mathrm{p}$ XPS data show that in the electrode polarized in $\mathrm{O}_{2}$ there is an enhancement of the $\mathrm{Cl}$ covalent contribution that appears at $200.8 \mathrm{eV}$ (which is already present in the fresh electrode although with a very small intensity). This result suggests that the oxygen reduction reaction leads to an increase of the $\mathrm{OH}^{-}$concentration inside the composite electrode that explains the charge transport in PPy at negative potentials.
\end{abstract}

(C) 2007 Elsevier Ltd. All rights reserved.

Keywords: A. Composites; C. Photoelectron spectroscopy; C. XAFS (EXAFS and XANES); D. Electrochemical properties

\section{Introduction}

Nanoparticle transition metal oxide electrodes are important materials due to their low cost, high-surface area, potential electrocatalytic activity for the oxygen reduction reaction (orr) and for being suitable materials to be used in fuel cell vehicles and light batteries. The use of conducting layers of polypyrrole PPy prevents the dissolution of metal oxide-based electrocatalysts, as we have reported recently in the case of copper manganite oxide [1]. In previous work we have confirmed the electrocatalytic activity for the orr of multilayer composite electrodes GC/PPy/PPy $(\mathrm{Ox}) / \mathrm{PPy}$, Ox being a copper- and manganese-containing spinel oxide with composition $\mathrm{Cu}_{1.4} \mathrm{Mn}_{1.6} \mathrm{O}_{4}[2,3]$ or a nickel- and

\footnotetext{
* Corresponding author. Tel.: +34 915625 126; fax: +34 915642431 .

** Corresponding author. Tel.: +56 27181 163; fax: +5626812108.

E-mail addresses: jfmarco@iqfr.csic.es (J.F. Marco), jgautier@usach.cl (J.L. Gautier).
} 
cobalt-containing spinel oxide with composition $\mathrm{Ni}_{0.3} \mathrm{Mn}_{2.7} \mathrm{O}_{4}$ [4,5]. During the orr on the $\mathrm{Cu}-\mathrm{Mn}$ oxide covered by a PPy film taking place at negative potentials, two important features were observed: (i) the conservation of the electrical conductivity of the composite film in conditions at which generally the polymer PPy is insulator and (ii) the occurrence of a remarkable electrochemical stability of the electrocatalyst at acidic pHs, a situation where the oxide is normally destroyed by electroreduction. This experimental behaviour can be explained by the local formation, by the orr, of $\mathrm{OH}^{-}$ions in the $\mathrm{PPy}\left(\mathrm{Cu}_{1.4} \mathrm{Mn}_{1.6} \mathrm{O}_{4}\right)$ inner layer, which arises from the consumption of the $\mathrm{H}^{+}$ions. Their presence plays a determining role for the anion exchange process between $\mathrm{OH}_{\mathrm{ads}}{ }^{-}$on $\mathrm{PPy}$ and $\mathrm{Cl}^{-}$in electrolytic solution, allowing for the preservation of good electrical conductivity of PPy [6]. In addition to that, the milder local activity medium improves the oxide stability.

In recent work [7] we have reported on the surface and structural characterization of GC/PPy/PPy $\left(\mathrm{Cu}_{1.4} \mathrm{Mn}_{1.6} \mathrm{O}_{4}\right) /$ PPy composite electrodes. The XPS data indicate that the $\mathrm{Cu}_{1.4} \mathrm{Mn}_{1.6} \mathrm{O}_{4}$ oxide contains $\mathrm{Cu}^{+}, \mathrm{Cu}^{2+}, \mathrm{Mn}^{3+}$ and $\mathrm{Mn}^{4+}$. On the other hand, XPS, XANES and EXAFS results indicate that when the oxide is incorporated into the PPy matrix, all the $\mathrm{Cu}^{+}$present in the original oxide suffers dismutation to give $\mathrm{Cu}^{2+}$ and metallic $\mathrm{Cu}^{0}$ giving place to the formation of a large number of vacancies $(\square)$ and to the approximate cation distribution: $\mathrm{Cu}_{1.17}{ }^{2+} \square_{0.23} \mathrm{Mn}_{1.20}{ }^{3+} \mathrm{Mn}_{0.40}{ }^{4+} \mathrm{O}_{4}$. The Mn K-edge XANES and EXAFS data reveal that, in this spinel-related oxide, $\mathrm{Mn}$ is present as $\mathrm{Mn}^{3+}$ and $\mathrm{Mn}^{4+}$ and that these cations occupy octahedral sites in the structure. The $\mathrm{Cu}$ K-edge EXAFS data indicate that copper exists in two oxidation states: $\mathrm{Cu}^{2+}$, which predominantly occupies tetrahedral sites in that structure but having a large degree of disorder in the second and higher coordination shells, and $\mathrm{Cu}^{0}$, which is in good agreement with the XPS data [7].

We report here on the use of X-ray photoelectron spectroscopy (XPS) and X-ray absorption spectroscopy (EXAFS and XANES) to determine the influence of the polarization conditions in oxygenated and non-oxygenated $\mathrm{KCl}$ aqueous solutions ( $\mathrm{pH}$ 2.2) on the bulk and surface structure of $\mathrm{GC} / \mathrm{PPy} / \mathrm{PPy}\left(\mathrm{Cu}_{1.4} \mathrm{Mn}_{1.6} \mathrm{O}_{4}\right) \mathrm{PPy}$ composite electrodes.

\section{Experimental}

The oxide synthesis and the preparation of the electrode with the composite structure GC/PPy/PPy(Ox)/PPy have been already described elsewhere [3,7]. The description of samples is given in Table 1. The amount of copper manganite incorporated in the electrode composite was $0.3 \mathrm{mg} \mathrm{cm}^{-2}[1,2]$.

The electrochemical behaviour of $\mathrm{GC} / \mathrm{PPy} / \mathrm{PPy}\left(\mathrm{Cu}_{1.4} \mathrm{Mn}_{1.6} \mathrm{O}_{4}\right) / \mathrm{PPy}$ composite electrodes was studied between -0.8 and $0.8 \mathrm{~V} / \mathrm{SCE}$ using cyclic voltammetry in $0.15 \mathrm{M} \mathrm{KCl}$ aqueous solution, at room temperature and $\mathrm{pH} 2.2 \mathrm{in} \mathrm{Ar}$ atmosphere. The $\mathrm{pH}$ of this solution was obtained using the adequate amount of $1 \mathrm{M} \mathrm{HCl}$. Three electrodes were analyzed: (i) a freshly prepared one denoted by $\mathrm{E}$, (ii) a cathodically polarized electrode at $-0.45 \mathrm{~V} / \mathrm{SCE}$ during $4 \mathrm{~h}$ in a solution saturated by $\operatorname{Ar}\left(\mathrm{P}_{1}\right)$ and (iii) an electrode polarized as electrode (ii) but in an oxygenated solution $\left(\mathrm{P}_{2}\right)($ see Table 1). An electrode polarized as $\mathrm{P}_{1}$ was treated by immersion in a $1 \mathrm{M} \mathrm{NaOH}$ solution.

The electrochemical equipment used was a three-electrode cell comporting the composite electrode, a Pt auxiliary electrode and SCE as the reference electrode. An Autolab PGSTAT 20 potentiostat equipped with a data acquisition system completed the electrochemical system.

The XPS data were recorded using a CLAM2 analyzer with three channeltrons under a vacuum better than $1 \times 10^{-8}$ Torr, using $\mathrm{Al} \mathrm{K} \alpha$ radiation and a constant analyzer transmission energy of $100 \mathrm{eV}$ for the wide scan spectra, and $20 \mathrm{eV}$ for the narrow scan spectra. All the spectra were recorded at a take-off angle of $90^{\circ}$. The binding energy (BE) values were referenced to the main C $1 \mathrm{~s}$ peak of the PPy ring (284.5 eV). The BE values are accurate to $\pm 0.2 \mathrm{eV}$. The relative atomic concentrations were calculated using tabulated atomic sensitivity factors [8].

The XANES and EXAFS measurements were performed at the Synchrotron Radiation Source at Daresbury Laboratory operating at $2.0 \mathrm{GeV}$ and an average current of $200 \mathrm{~mA}$. The data were collected at $298 \mathrm{~K}$ using a Si(llll) double crystal order sorting monochromator in fluorescence mode using 50\% harmonic rejection. The energy scale

Table 1

Description of samples

\begin{tabular}{ll}
\hline Designation of sample & Composition \\
\hline $\mathrm{E}$ & $\mathrm{GC} / \mathrm{PPy} / \mathrm{PPy}\left(\mathrm{Cu}_{1.4} \mathrm{Mn}_{1.6} \mathrm{O}_{4}\right) / \mathrm{PPy}$ \\
$\mathrm{P}_{1}$ & $\mathrm{GC} / \mathrm{PPy} / \mathrm{PPy}\left(\mathrm{Cu}_{1.4} \mathrm{Mn}_{1.6} \mathrm{O}_{4}\right) / \mathrm{PPy}$ polarized at $-0.45 \mathrm{~V} / \mathrm{ECS}$ in a $0.15 \mathrm{M} \mathrm{KCl} \mathrm{solution} \mathrm{at} \mathrm{pH} 2.2$ saturated in Ar \\
$\mathrm{P}_{2}$ & $\mathrm{GC} / \mathrm{PPy} / \mathrm{PPy}\left(\mathrm{Cu}_{1.4} \mathrm{Mn}_{1.6} \mathrm{O}_{4}\right) / \mathrm{PPy}$ polarized at $-0.45 \mathrm{~V} / \mathrm{ECS}$ in a $0.15 \mathrm{M} \mathrm{KCl}$ solution at $\mathrm{pH} 2.2$ saturated in $\mathrm{O}_{2}$ \\
\hline
\end{tabular}


was calibrated using a $6 \mu \mathrm{m} \mathrm{Mn}$ foil in the case of the manganese K-edge and a $6 \mu \mathrm{m} \mathrm{Cu}$ foil for the copper K-edge. The position of the $\mathrm{Mn}$ foil edge was taken at $6538 \mathrm{eV}$ and that of the $\mathrm{Cu}$ foil edge at $8982 \mathrm{eV}$. All the manganese and copper XANES data were referred to these two values. All the edges were recorded at least twice and at different times separated by several hours but within the lifetime of the beam. The reproducibility in the determination of the edge positions was found to be better than $0.2 \mathrm{eV}$. The edge profiles were separated from the EXAFS data and, after subtraction of the linear pre-edge background, normalized to the edge step. The EXAFS oscillations were isolated after background subtraction of the raw data using the Daresbury program EXBACK and converted into $k$ space. The data were weighted by $k^{3}$, where $k$ is the photoelectron wavevector, to compensate for the diminishing amplitude of the EXAFS at high $k$. The data were fitted using the non-linear squares minimisation program EXCURV90 [9] which calculate the theoretical function using the fast curved wave theory [10].

\section{Results and discussion}

\subsection{Electrochemical behaviour}

Fig. 1(curve 1) shows the cyclic voltammogram of the freshly prepared electrode in $0.15 \mathrm{M} \mathrm{KCl}$ aqueous solution, at room temperature and $\mathrm{pH} 2.2$, in Ar atmosphere. It displays the classic electrochemical behaviour of composite electrodes characterized by insertion/expulsion processes of $\mathrm{Cl}^{-}$doping anions into/from polymer PPy matrix. The positions and heights of the peaks varied with the scan rate but they remained unchanged with the number of cycles. The shape and characteristics of voltammograms obtained on this electrode at the 100th scan were practically identical to those recorded at the first scan. The voltammograms recorded on composite electrodes previously polarized at $-0.45 \mathrm{~V} / \mathrm{SCE}$ prior to the cyclic voltammetry experiment (Fig. 1, curve 2), in the same conditions of the fresh one, showed that after a prolonged polarization at negative potentials almost all $\mathrm{Cl}^{-}$anions are expulsed from the PPy matrix leading to an important loss of conductivity. Consequently, its electrochemical properties are quasi null. The expulsion of the chloride anions from the PPy matrix at negative potentials such as $-0.45 \mathrm{~V} / \mathrm{SCE}$ would lead to a reduction of the conjugated chain and consequently to a loss in conductivity. However, regarding the results obtained by Van Dyke in the case of acetonitrile [6], it is possible to extend the conductive state of PPy films to very highnegative potential such as $-1.1 \mathrm{~V} / \mathrm{SCE}$ using a simple chemical treatment consisting of immersion of the electrode in $\mathrm{NaOH}$ aqueous solution. It has been suggested that such treatment [6], gives rise to an exchange reaction between the $\mathrm{OH}^{-}$and $\mathrm{Cl}^{-}$ions placed inside the polypyrrole matrix. Therefore it is possible to accept that at negative potentials the PPy conductivity is assured by the $\mathrm{OH}^{-}$anions. In fact, when the blocked electrodes were treated via immersion into $1 \mathrm{M} \mathrm{NaOH}$ solution, their electrochemical properties were virtually the same than those exhibited by the fresh electrode (Fig. 1, curve 3). On the other hand, when the composite electrode is polarized at the same potential $(-0.45 \mathrm{~V} / \mathrm{SCE})$ in the solution but now saturated with $\mathrm{O}_{2}$, the voltammogram is similar to that obtained after $\mathrm{NaOH}$

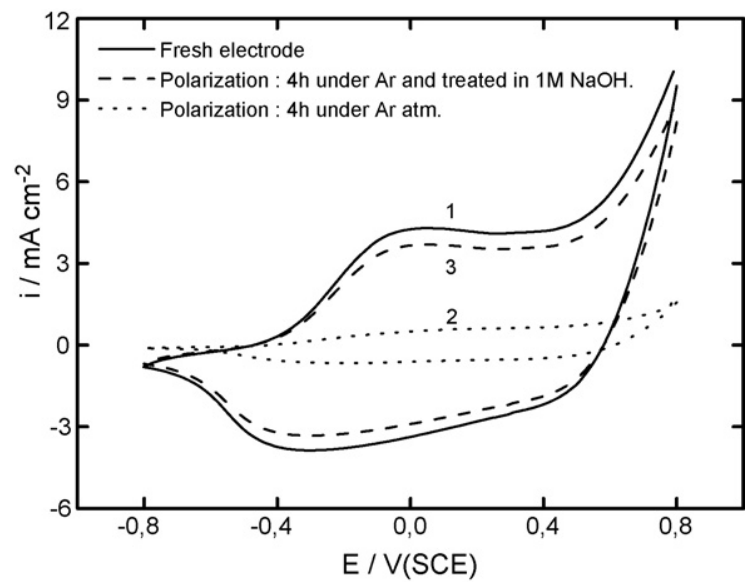

Fig. 1. Cyclic voltammograms recorded from the fresh electrode and from the electrodes polarized for $4 \mathrm{~h}$ at $-0.45 \mathrm{~V} / \mathrm{SCE}$ under an inert atmosphere in the presence and in the absence of treatment in $1 \mathrm{M} \mathrm{NaOH}$ solution during $2 \mathrm{~h}$. Electrolyte: $0.15 \mathrm{M} \mathrm{KCl} \mathrm{solution}$, $\mathrm{pH} 2.2$, room temperature, scan rate $v=10 \mathrm{mV} \mathrm{s}^{-1}$. 


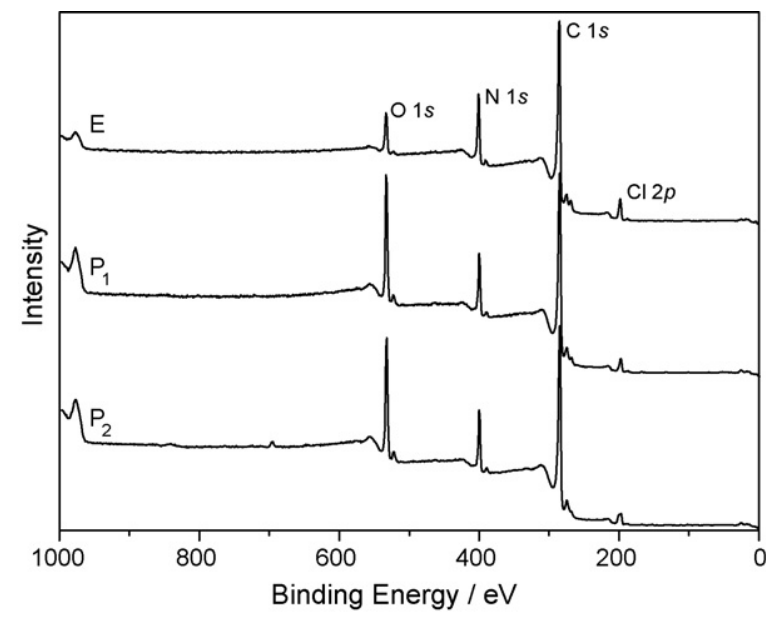

Fig. 2. Wide scan XPS spectra recorded from samples $E, P_{1}$ and $P_{2}$.

treatment (Fig. 1, curve 3) confirming the $\mathrm{OH}^{-}$formation during the electrocatalytical orr $\mathrm{O}_{2}+4 \mathrm{H}^{+}+4 \mathrm{e}^{-} \rightarrow 2 \mathrm{H}_{2} \mathrm{O}$ on $\mathrm{Cu}_{1.4} \mathrm{Mn}_{1.6} \mathrm{O}_{4}$ particles incorporated to $\mathrm{PPy}$. The composite electrode is particularly stable in acidic solution ( $\mathrm{pH}$ 2.2) because the $\mathrm{H}^{+}$ions are consumed by the orr favouring the increase of local $\mathrm{pH}$ and stabilizing the oxide. The $\mathrm{OH}^{-}$ ions existing in the pores of PPy may play a role similar to that played by those involved in the chemical treatment in $\mathrm{NaOH}$ solution cited before.

\subsection{Spectroscopic characterization}

Fig. 2 shows the wide scan XP spectra recorded from the polarized electrodes $\mathrm{P}_{1}$ and $\mathrm{P}_{2}$ as well as from the freshly prepared, non-polarized PPy/PPy $\left(\mathrm{Cu}_{1.4} \mathrm{Mn}_{1.6} \mathrm{O}_{4}\right) / \mathrm{PPy}$ electrode (E). The spectra recorded from samples $\mathrm{E}, \mathrm{P}_{1}$ and $\mathrm{P}_{2}$ show the signals for $\mathrm{C} 1 \mathrm{~s}, \mathrm{~N} 1 \mathrm{~s}$ and $\mathrm{Cl} 2 \mathrm{p}$, as expected. All the spectra show an extra oxygen contribution that is more intense on the polarized electrodes, which we attribute to adsorbed oxygen at the surface of the electrodes. Since the oxide loading of the electrodes is small and the oxide particles are covered by a protective PPy overlayer (which must attenuate most of the photoelectron flux coming from the oxide particles) it is difficult to observe in these general spectra any significant signal in the $\mathrm{Cu} 2 \mathrm{p}$ and $\mathrm{Mn} 2 \mathrm{p}$ spectral regions above the spectral background. The $\mathrm{N} 1 \mathrm{~s}$ spectra recorded from samples $\mathrm{E}, \mathrm{P}_{1}$ and $\mathrm{P}_{2}$ were all similar amongst themselves and also similar to those reported previously for the system $\mathrm{Ni}-$ $\mathrm{Co}-\mathrm{O} / \mathrm{PPy}$ [11] which is not shown here. Several contributions were observed which correspond to pyrrolium nitrogen atoms $(-\mathrm{NH}-; \mathrm{BE}=399.7 \mathrm{eV})$, charged nitrogen atoms $\left(-\mathrm{N}^{+} \mathrm{N}-\right)$ belonging to the pyrrole structure (characterized by BE's of 401.2 and $402.8 \mathrm{eV})$ [11] and $=\mathrm{N}$ - structures $(\mathrm{BE}=397.8 \mathrm{eV})$ [12]. The $\mathrm{Cl} 2 \mathrm{p}$ spectra recorded from samples $\mathrm{E}$ and $\mathrm{P}_{1}$ were very similar to those reported previously [11] (Fig. 3). Three spin-orbit doublets characterized by a BE of the $\mathrm{Cl} 2 \mathrm{p}_{3 / 2}$ level of 197.2, 198.9 and $200.8 \mathrm{eV}$ were observed. The lowest and the highest BE components correspond to ionic and covalent chlorine species $\left(\mathrm{Cl}^{-}\right.$and $\left.-\mathrm{Cl}\right)$, respectively [12], while the contribution appearing at $198.9 \mathrm{eV}$ could be associated to an intermediate situation between that of an ionic $\mathrm{Cl}^{-}$species and the covalent $-\mathrm{Cl}$ species, arising from an increase in the number of positively charged nitrogen atoms in the polymer chain. The spectrum recorded from sample $\mathrm{P}_{2}$ is very different and shows a considerable enhancement of the intensity of the contribution corresponding to the covalent $-\mathrm{Cl}$ species (Fig. 3) which in this sample accounts for ca. 56\% of the spectral area. The relative contribution of the ionic $\mathrm{Cl}^{-}$species to the total $\mathrm{Cl} 2 \mathrm{p}$ signal has decreased in this sample with respect to the contribution observed in the fresh electrode (sample E). This result illustrates the determining role of the $\mathrm{O}_{2}$ presence on the increase of the covalent $-\mathrm{Cl}$ species strongly linked to the PPy chain in the composite electrodes. The chloride anions favour the electrical conductivity of PPy so contributing to the electrocatalytical behaviour of composite electrodes at negative potentials as previously reported [3]. The relative atomic concentrations derived from the spectra are shown in Table 2. The experimental N/C ratio, which is very similar for all samples $(0.16-0.17)$, is lower than that calculated for a pyrrole unit in $\mathrm{PPy}(\mathrm{N} / \mathrm{C}=0.25)$. The difference can be attributed to the presence of an adventitious hydrocarbon layer on the surface of the electrode. Using the $\mathrm{N} / \mathrm{C}$ ratios, the $\mathrm{C}_{\mathrm{ppy}}$ corresponds to $66 \%$ of the total carbon $\mathrm{C}\left(\mathrm{C}=\mathrm{C}_{\mathrm{ppy}}+\mathrm{C}_{\mathrm{other}}\right)$. On the other 


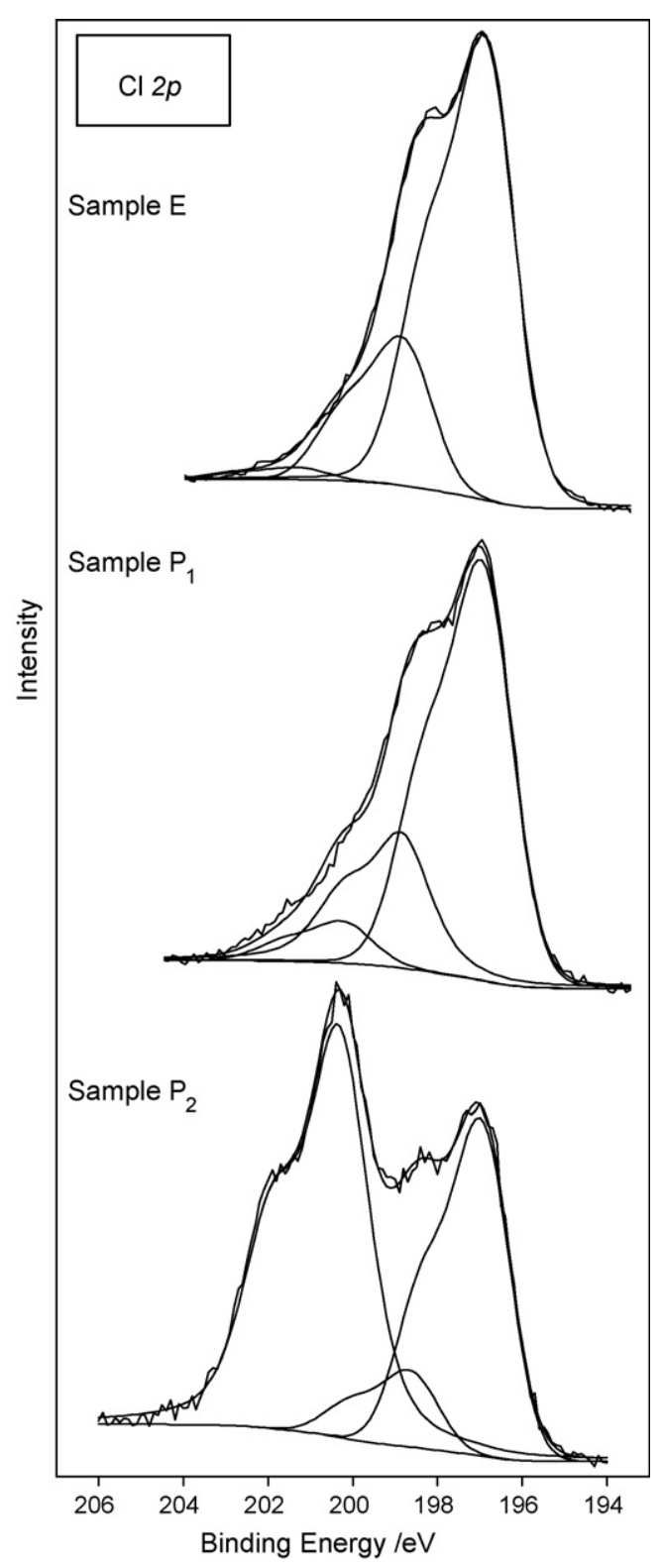

Fig. 3. $\mathrm{Cl} 2 \mathrm{p}$ spectrum recorded from samples $\mathrm{E}, \mathrm{P}_{1}$ and $\mathrm{P}_{2}$.

hand, the calculated $\mathrm{N} / \mathrm{Cl}$ ratios vary between 0.13 and 0.24 , values that are similar to those of the non-polarized electrodes [7]. It can be also observed that the surface of the electrodes $P_{1}$ and $P_{2}$ contains much more oxygen than the fresh electrode (E). This oxygen contribution disappears very rapidly after the effect of $\mathrm{Ar}^{+}$sputtering. Actually its intensity is reduced to a tenth of its initial intensity just after removing the outermost $2 \mathrm{~nm}$ from the surface by $\mathrm{Ar}^{+}$

Table 2

Relative atomic concentrations obtained from the XPS data

\begin{tabular}{lllll}
\hline Sample & $\mathrm{N} / \mathrm{C}$ & $\mathrm{Cl} / \mathrm{C}$ & $\mathrm{O} / \mathrm{C}$ & $\mathrm{N} / \mathrm{Cl}$ \\
\hline $\mathrm{E}$ & 0.17 & 0.04 & 0.08 & 0.24 \\
$\mathrm{P}_{1}$ & 0.16 & 0.02 & 0.21 & 0.13 \\
$\mathrm{P}_{2}$ & 0.16 & 0.03 & 0.23 & 0.19 \\
\hline
\end{tabular}




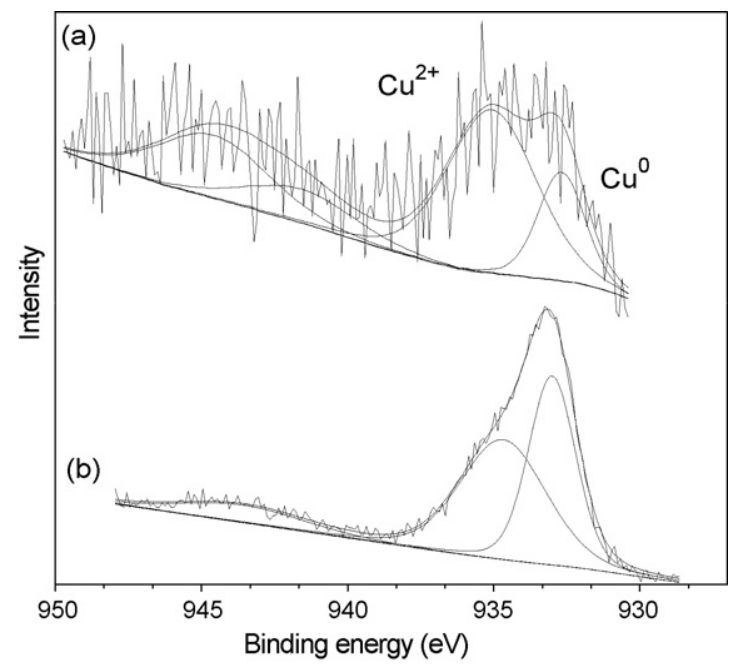

Fig. 4. $\mathrm{Cu} 2 \mathrm{p}_{3 / 2}$ spectra recorded from (a) sample $\mathrm{E}$ and (b) sample $\mathrm{P}_{1}$.

bombardment. The main component in the $\mathrm{O} 1 \mathrm{~s}$ spectra recorded from these samples appears at $533.2 \mathrm{eV}$, with a smaller component at $531.2 \mathrm{eV}$. These binding energies are characteristic of adsorbed water and hydroxyl groups, respectively, and can come from the electrolyte in which these two samples have been treated electrochemically. In the case of the sample $\mathrm{P}_{2}$ another source of water can come from the oxygen reduction reaction mentioned before.

As mentioned in Section 1, previously reported results [7] have indicated that the powdered oxide $\mathrm{Cu}_{1.4} \mathrm{Mn}_{1.6} \mathrm{O}_{4}$ contains $\mathrm{Mn}^{3+}, \mathrm{Mn}^{4+}, \mathrm{Cu}^{+}$and $\mathrm{Cu}^{2+}$. The XPS Cu $2 \mathrm{p}_{3 / 2}$ spectra recorded from the polarized electrodes also show the presence of metallic $\mathrm{Cu}$ and $\mathrm{Cu}^{2+}$ as the fresh electrode [7]. Regarding the XPS $\mathrm{Cu} 2 \mathrm{p}_{3 / 2}$ spectrum recorded from the polarized electrode $P_{1}$ (Fig. 4) it is possible to observe that the metallic copper signal has increased significantly respect to that observed in the spectrum of the freshly prepared composite electrode $\mathrm{E}$. This indicates that a fraction of the $\mathrm{Cu}^{2+}$ initially present in the composite electrode has suffered reduction to metallic $\mathrm{Cu}$ as a consequence of the electrode being cathodically polarized.

Fig. 5 shows the Mn K-edge XANES recorded from samples $\mathrm{E}, \mathrm{P}_{1}$ and $\mathrm{P}_{2}$ together with those of the reference compounds $\mathrm{MnO}, \mathrm{Mn}_{2} \mathrm{O}_{3}$ and $\mathrm{MnO}_{2}$. As already reported, the shape of the edge spectral features recorded from the electrodes are all characteristic of an octahedral spinel cation [14]. The position of the Mn K-edge of all the composite electrodes is situated between that of $\mathrm{Mn}_{2} \mathrm{O}_{3}$ and $\mathrm{MnO}_{2}$ indicating that the composite electrode contains both $\mathrm{Mn}^{3+}$ and $\mathrm{Mn}^{4+}$ placed only in $\mathrm{B}$ sites of the spinel structure. It is also evident that the absorption edge corresponding to the

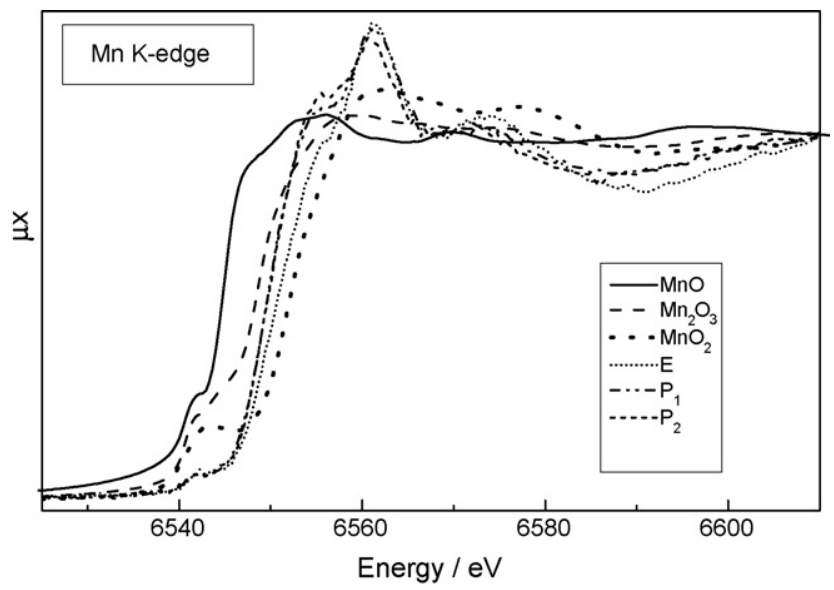

Fig. 5. Mn K-edge XANES recorded from samples E, $\mathrm{P}_{1}$ and $\mathrm{P}_{2}$ and the reference compounds $\mathrm{MnO}, \mathrm{Mn}_{2} \mathrm{O}_{3}$ and $\mathrm{MnO}_{2}$. 

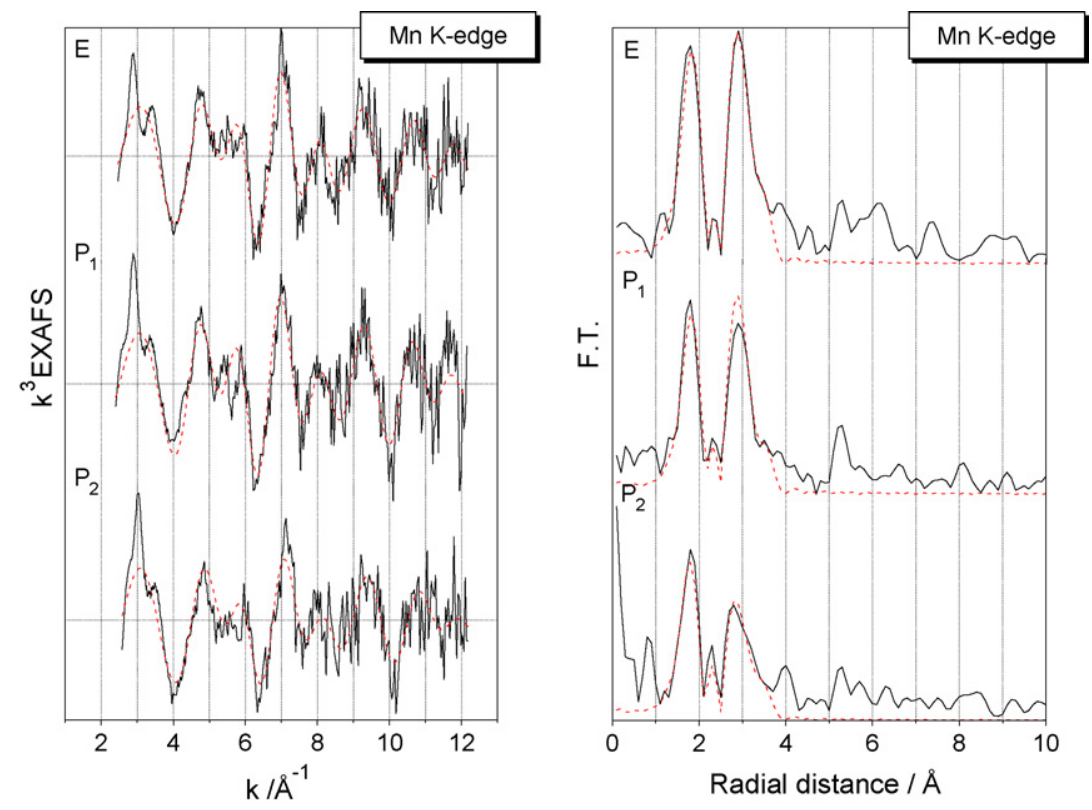

Fig. 6. Left: Mn K-edge EXAFS recorded from samples E, $\mathrm{P}_{1}$ and $\mathrm{P}_{2}$. Right: the corresponding Fourier transforms of the spectra are shown on the left. The solid line depicts the experimental data, while the dashed lines represents the fitted curve.

polarized electrodes $\left(\mathrm{P}_{1}\right.$ and $\left.\mathrm{P}_{2}\right)$ is shifted to lower energies than that of the non-polarized electrodes (sample $\mathrm{E}$ ) showing that the samples $\mathrm{P}_{1}$ and $\mathrm{P}_{2}$ contain more $\mathrm{Mn}^{3+}$ than the fresh electrode $\mathrm{E}$. This indicates that the $\mathrm{Mn}^{4+}$ ions are reduced to $\mathrm{Mn}^{3+}$ ions as a consequence of the electrodes being cathodically polarized.

The Mn K-edge EXAFS recorded from samples $E, P_{1}$ and $P_{2}$ together with their corresponding Fourier transforms are shown in Fig. 6. These Fourier transforms are characterized by a first shell situated at ca. $2 \AA$ and a second shell situated at ca. $2.9 \AA$, which is consistent with what was observed for transition metal cations occupying the octahedral sites of a spinel-related structure [13-17]. Considering that the XANES results suggested the existence of both $\mathrm{Mn}^{3+}$ and $\mathrm{Mn}^{4+}$ the EXAFS was fitted to a model which considered the presence of these two oxidation states of Mn. The results obtained from the fit using a procedure already described [15] are shown in Table 3. The shortest Mn-O distance at ca. $1.90 \AA$ is characteristic of $\mathrm{Mn}^{4+}$ [18]. Since $\mathrm{Mn}^{3+}$ is a JT-cation, a distorted octahedral geometry results which are characterized by four short $\mathrm{Mn}-\mathrm{O}$ distances of about $1.90 \AA$ and two longer distances of about $2.2-2.3 \AA$ [18]. Therefore, the distance at ca. $1.90 \AA$ also stands for the shorter $\mathrm{Mn}^{3+}-\mathrm{O}$ distance while the distance at 2.18$2.21 \AA$ corresponds to the longer $\mathrm{Mn}^{3+}-\mathrm{O}$ distance [19]. Since the ratio of the corresponding coordination numbers for each distance is representative of the $\mathrm{Mn}^{3+} / \mathrm{Mn}^{4+}$ ratio, the results presented in Table 3 indicate that the percentage of $\mathrm{Mn}^{3+}$ increases in the order $\mathrm{E}<\mathrm{P}_{1}<\mathrm{P}_{2}$. This is in good agreement with what was suggested by the XANES data. It is also observed that the intensity of the second shell diminishes in amplitude in the order $\mathrm{E}<\mathrm{P}_{1}<\mathrm{P}_{2}$ suggesting the existence of disorder in the second shell. In fact the FT corresponding to the electrode $\mathrm{P}_{2}$ resembles more that characteristic of the $\mathrm{Cu}-\mathrm{Mn}$ amorphous oxides with proto-spinel structures [17].

Table 3

Results regarding fitting the Mn-K edge EXAFS data

\begin{tabular}{lllll}
\hline Sample & Atom type & Coordination number & $R(\AA)$ & $2 \sigma^{2}\left(\AA^{2}\right)$ \\
\hline $\mathrm{E}$ & $\mathrm{O}$ & 6 & 1.92 & 0.023 \\
& $\mathrm{O}$ & 2 & 2.21 & 0.011 \\
$\mathrm{P}_{1}$ & $\mathrm{O}$ & 5.5 & 1.90 & 0.024 \\
& $\mathrm{O}$ & 2 & 2.20 & 0.012 \\
$\mathrm{P}_{2}$ & $\mathrm{O}$ & 5.5 & 1.90 & 0.026 \\
& $\mathrm{O}$ & 2.5 & 2.18 & 0.013 \\
\hline
\end{tabular}


The $\mathrm{Cu}$ K-edge XANES and EXAFS data obtained from sample E (not shown) were compatible with the presence of $\mathrm{Cu}^{0}$ and of $\mathrm{Cu}^{2+}$, the latter occupying tetrahedral sites in the spinel-related structure, a situation that was described and reported elsewhere [7]. The data recorded from the polarized electrodes $\mathrm{P}_{1}$ and $\mathrm{P}_{2}$ were qualitatively similar to those recorded from sample E. In the case of sample $\mathrm{P}_{2}$ the data showed a remarkable increase of the $\mathrm{Cu}^{0} / \mathrm{Cu}^{2+}$ ratio with respect to the E sample ( 0.36 and 0.28 , respectively). As opposed to what was observed by XPS, in the case of sample $\mathrm{P}_{1}$ no increase of the $\mathrm{Cu}^{0} / \mathrm{Cu}^{2+}$ was observed. This discrepancy can be explained in terms of the surface sensitivity of the XPS technique versus the bulk character of the XAS technique.

\section{Conclusions}

Two important conclusions can be pointed out:

(i) When the composite electrodes are polarized at $-0.45 \mathrm{~V} / \mathrm{ECS}$ in $0.15 \mathrm{M} \mathrm{KCl}$ solution ( $\mathrm{pH} 2.2$ ) under $\mathrm{O}_{2}$ or $\mathrm{Ar}$ atmosphere, the $\mathrm{Mn}^{3+} / \mathrm{Mn}^{4+}$ ratio increases, which suggests that some of the $\mathrm{Mn}^{4+}$ has been reduced to $\mathrm{Mn}^{3+}$ during the process of cathodic polarization. A similar effect has been pointed out for copper since a fraction of the $\mathrm{Cu}^{2+}$ present in the freshly prepared composite electrode appears to be reduced to $\mathrm{Cu}^{0}$ in the polarized electrodes.

(ii) The XPS results presented in this paper indicate that the chemical nature of the $\mathrm{Cl}$ and $\mathrm{N}$ species in the composite electrode are not altered by polarization in Ar atmosphere. However, when the composite electrode is polarized under the same electrochemical conditions in an $\mathrm{O}_{2}$ atmosphere, there is a clear enhancement of the covalent $-\mathrm{Cl}$ species. This result suggests that the orr leads to an increase in the concentration of $\mathrm{OH}^{-}$inside the composite electrode which in turn explains the charge transport in PPy at negative potentials.

\section{Acknowledgements}

The authors acknowledge financial support from the Chilean Agency CONICYT (Fondecyt 1050178 and 7060205), CSIC/USACH program and ECOS/CONICYT (Action C04E02).

\section{References}

[1] H. Nguyen Cong, K. El Abbassi, P. Chartier, Electrochem. Lett. 3 (2000) 192.

[2] H. Nguyen Cong, K. El Abbassi, P. Chartier, J. Electrochem. Soc. 149 (2002) A525.

[3] H. Nguyen Cong, K. El Abbassi, J.L. Gautier, P. Chartier, Electrochim. Acta 50 (2005) 1369.

[4] H. Nguyen Cong, V. de la Garza Guadarrama, J.L. Gautier, P. Chartier, J. New Mater. Electrochem. Syst. 5 (2002) 35.

[5] H. Nguyen Cong, V. de la Garza Guadarrama, J.L. Gautier, P. Chartier, Electrochim. Acta 48 (2003) 2389.

[6] L.S. van Dyke, S. Kuwabata, C.R. Martin, J. Electrochem. Soc. 140 (1993) 2754.

[7] J.F. Marco, J.R. Gancedo, H. Nguyen Cong, M. del Canto, J.L. Gautier, Solid State Ionics 177 (2006) 1381.

[8] C.D. Wagner, L.E. Davis, M.V. Zeller, J.A. Taylor, R.M. Raymond, L.H. Gale, Surf. Interf. Anal. 3 (1981) 211.

[9] N. Binsted, S. Gurman, J. Campbell, Laboratory EXCURV90 Program, Daresbury Laboratory, 1990.

[10] S.J. Gurman, N. Binsted, I. Ross, J. Phys. C 17 (1984) 143.

[11] J.L. Gautier, J.F. Marco, M. Gracia, J.R. Gancedo, V. de la Garza Guadarrama, H. Nguyen Cong, P. Chartier, Electrochim. Acta 48 (2002) 119.

[12] K.L. Tan, B.T.G. Tan, E.T. Kang, K.G. Neoh, J. Chem. Phys. 94 (1991) 5382.

[13] D.A. Kukuznyak, S.-W. Han, M.-H. Lee, K.A. Omland, M.C. Gregg, E.A. Stern, F.S. Ohuchi, J. Vac. Sci. Technol. A 19 (2001) 1923.

[14] V.G. Harris, N.C. Koon, C.M. Williams, Q. Zhang, M. Abe, J. Appl. Phys. 79 (1996) 4561.

[15] J.F. Marco, J.R. Gancedo, M. Gracia, J.L. Gautier, E. Ríos, H.M. Palmer, C. Greaves, F.J. Berry, J. Mater. Chem. 11 (2001) 3087.

[16] M. Gracia, J.F. Marco, J.R. Gancedo, J.L. Gautier, E.I. Ríos, N. Menéndez, J. Tornero, J. Mater. Chem. 13 (2003) 844.

[17] P.A. Wright, S. Natarajan, J.M. Thomas, P.L. Gai-Boyes, Chem. Mater. 4 (1992) 1053.

[18] B. Ammundsen, D.J. Jones, J. Rozière, F. Villain, J. Phys. Chem. 102 (1998) 7939.

[19] H. Yamaguchi, A. Yamada, H. Uwe, Phys. Rev. B 58 (1998) 8. 